\title{
OPERATIVE MANAGEMENT OF TRAUMATIC INTRACRANIAL HEMORRHAGE*
}

\author{
E. S. GURdjIAN, M.D.
}

Attending Neurosurgeon, Grace HospitaI; Associate Attending Surgeon, Receiving HospitaI; Extramural Lecturer, Graduate Medical School, University of Michigan

DETROIT, MICHIGAN

$A^{\mathrm{LT}}$ THOUGH the majority of patients with head injury do well on conservative treatment, a goodly number present signs and symptoms that may spell operative intervention. With the present day tendency of over-conservatism in the management of head injury it is important to evaluate such signs and symptoms and effect operative intervention as soon as it is justifrable or necessary. It is always a painful experience to note at autopsy a pathologic condition which could have been treated by operation with fair degree of probability for a successful outcome.

The pathologic possibilities in traumatic intracranial hemorrhage are given in the following tabulation:

I. Intracranial hemorrhage

A. Extradural, due to rupture of meningeal vessels, sinuses and diploe

B. Intradural, due to pial tears, bruises or laceration of nervous tissue

(I) Subdural

(a) Acute

(b) Chronic subdural hematoma

(2) Subarachnoid

(a) Generalized

(b) Localized

(3) Intraparenchymatous

(a) Petechial

(b) Massive

II. Bruising or laceration of nervous tissue, with or without fracture of the skull.
III. Subdural accumulation of spinal fluid simulating intracranial hemorrhage.

In the above classification of listed conditions best trcated by operation are extradural hemorrhage, acute subdural hemorrhage with signs, chronic subdural hematoma and subdural collection of spinal fluid. Because of similarity of symptoms and signs, some cases on exploration may show only contusions and lacerations of neural tissue or a wet brain with no demonstrable gross pathology. It must be admitted that in a great many there may be a combination of lesions.

This paper is based on eighty-one operated cases during a frve and one-half year period from September 1930, to March 1936. I have included in this group only those cases which were treated by myself, and have not attempted an all-inclusive statistical survey. The distribution of pathology is as follows: 19 cases with extradural hemorrhage; i cases of acute subdural hemorrhage; I3 cases of chronic subdural hematoma; 13 cases of subdural collection of spinal fluid; 15 cases of wet brain, cerebral contusions, subarachnoid hemorrhage (any one or a combination of aII). Before discussing these pathologic entities, I should like to consider briefly the various signs and symptoms in head injury which spell operative intervention. These may be grouped under the following headings: first, changes in the state of consciousness; second, changes in vital functions; third, changes in pupillary size and ocular function; fourth, abnormal

* From the Department of Neurosurgery, Grace and Receiving Hospitals, Detroit, Michigan. 
neurologic findings; fifth, changes in spinal fluid findings.

I. Changes in the State of Consciousness.

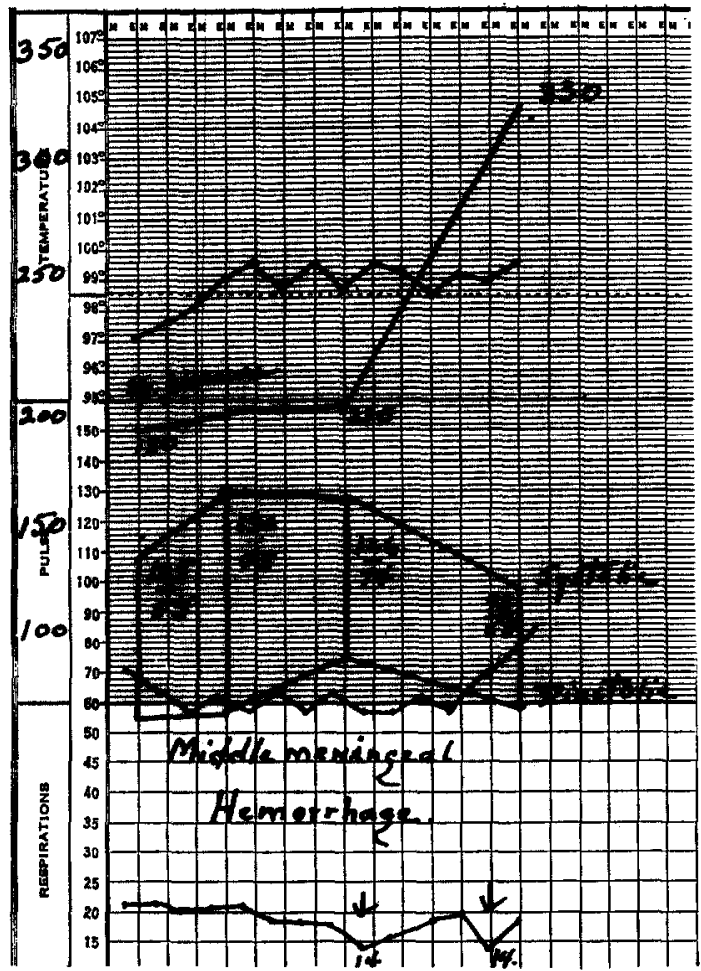

Chart I. Composite chart of the vital functions and spinal fluid pressure in a case of middle meningeal hemorrhage. Note that blood pressure does not rise with increasing spinal fluid pressure. The respiratory and pulse rates became depressed on several occasions. The initial spinal fluid pressure in this case is low but this does not rule out middle meningeal hemorrhage of operable proportions.

Changes in the state of consciousness are very important. A normal state of consciousness is always a favorable sign and is a counterindication for operative intervention except in cases with mechanical defects (simple and compound depressions). Progressive return of consciousness is practically always a counterindication for operation. Progressive drowsiness, periods of conscious states alternating with periods of drowsiness, and disorientation may signify operative intervention, if certain other signs obtain. A lucid interval followed by drowsiness and unconsciousness is an important syndrome, but it does not always signify middle meningeal hemorrhage. I have seen it frequently with subdural hemorrhage, subdural accumulation of spinal fluid and edema of the brain.

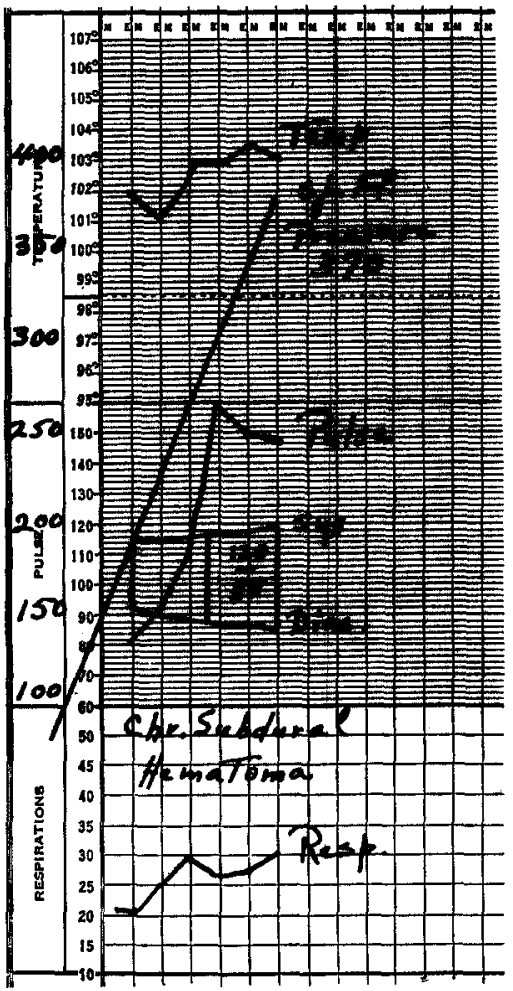

Chart II. A case of middle meningeal hemorrhage with initial low spinal fluid pressure which became more depressed in the course of seventy-two hours, when the patient was operated upon. Even though a low spinal fluid pressure is unusual, it can occur in cases of middle meningeal hemorrhage. This is the only instance in the series showing a pressure under 300 at the time of operation. There is a blood pressure rise while the spinal fluid pressure is lowering. Blood pressure readings as an index of intracranial pressurc seem worthless.

2. Changes in Vital Functions. The pulse, respiration, temperature and blood pressure are important both from a prognostic and a diagnostic standpoint. At times the pulse rate is low to an alarming degree. A low pulse rate is frequently associated with enlarging clots such as from extradural or subdural hemorrhage, although, a rate of 40 to 55 is occasionally seen with an otherwise normal patient 
(including normal spinal fluid pressure). Such a case is kept under close observation for other signs of increased intracranial

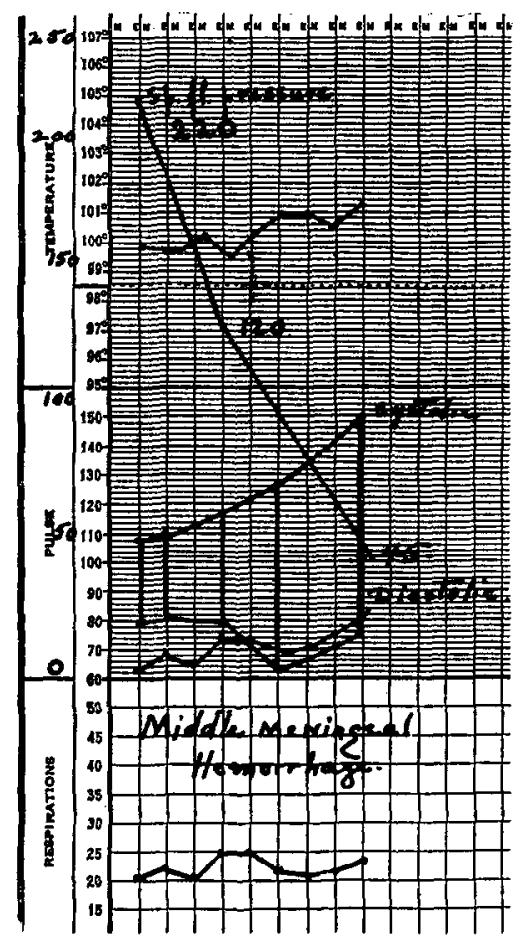

Chart III. A typical case of chronic subdural hematoma which has been allowed to go too long. There is incrcase in temperature, pulse and respirations. There is also a definite increase in the spinal fluid pressure. At this stage the patient is usually unconscious and may or may not have localizing signs. The presence of increased spinal fluid pressure in an otherwise normal person (except for the state of unconsciousness) is very suggestive of chronic subdural hematoma. A history of injury to the head may or may not be obtained.

pressure. Usually the pulse rate rises to normal from a few to ten days. Of course the mere presence of a low pulse rate is not an indication for operation, but a lowering rate is an important factor in establishing its advisability. In conjunction with other findings (such as increasing drowsiness) it becomes a potent factor favoring intervention.

The respiratory rate and the temperature are more frequently of prognostic significance. Increase in respiration soon after trauma spells very poor prognosis. High temperature (above I04 degrees rectally) soon after trauma, is also of serious import.

I have found blood pressure readings of no significant help in estimating the degree of intracrenial pressure. On the whole, blood pressure readings are worthwhile only to establish the condition of circulation. One type of blood pressure reading has been found to spell very poor prognosis in the adult, i.e., when the pulse pressure equals the systolic pressure.

3. Cbanges in Pupillary Size and Ocular Function. The condition of the pupils, their size, their reaction to light and inequalities, if present, are important both from a prognostic and a diagnostic standpoint. A dilated pupil is practically always on the same side as the lesion, for which an operation may be contemplated. However, in a small number of cases, the dilated pupil may be found on the opposite side, as was true in one of our cases of middle meningeal hemorrhage. Extraocular paralysis, when present, usually means pathology on the same side, when an operation is contemplated.

The prognostic significance of pupillary findings cannot be denied. Dilated and frxed pupils spell grave outcome. The same is to a less degree true in cases of constricted and fixed pupils. However, one can usually tell from the general appearance of the patient that he is in grave danger and such pupillary findings are therefore corroborative.

The presence of pupillary inequality as such is not a criterion for operation. When it appears in a case with other symptoms and signs favoring intervention, pupillary inequality helps to locate the pathology more accurately.

4. Neurologic Findings. Neurologic findings when present serve two purposes: first, the localization of pathology, and second, on the basis of the mode of development of such findings, they serve as indication for operative intervention. Hemiplegia, hemiparesis, Jacksonian convulsions, and 
sensory changes, when detectable, usually denote pathologic changes in a definite portion of the nervous system. However, because of the great incidence of contrecoup lesions in head injury, neurologic findings of exact localization are at times quite misleading. Hemiparesis or hemiplegia on the same side as the cerebral clot different significance from a hemiplegia developing slowly and becoming complete within twelve to twenty-four hours. In the former, the hemiplegia is most probably indicative of contusion or laceration of the motor cortex. When hemiplegia develops slowly, the possibility of an enlarging clot as a causative factor is apparent. Hemi-

TABLE I

SYNOPSIS OF CASES WITH MIDDLE MENINGEAL HEMORRHAGE (OPERATED)

\begin{tabular}{|c|c|c|c|c|c|c|c|c|}
\hline No. & Age & Pupils & $\begin{array}{l}\text { Extra- } \\
\text { Ocular } \\
\text { Palsies }\end{array}$ & Lucid Interval & $\begin{array}{l}\text { Pulse } \\
\text { Rate }\end{array}$ & Focal Signs & $\begin{array}{l}\text { Spinal } \\
\text { Fluid }\end{array}$ & Results \\
\hline I & 55 & Equal & None & None & $50-60$ & Bilateral Babinski & Bloody $35^{\circ}$ & Recovered \\
\hline 2 & I3 & $\begin{array}{ll}\text { At first un- } \\
\text { equal } & \text { left } \\
\text { larger } & \end{array}$ & None & $\begin{array}{l}7 \text { days with periods } \\
\text { of disorient. No } \\
\text { unconsc. }\end{array}$ & $50-55$ & $\begin{array}{l}\text { Right Babinski } \\
\text { Right upper } \operatorname{limb} \\
\text { paresis }\end{array}$ & $\begin{array}{l}\text { Bloody } 180- \\
300\end{array}$ & Recovered \\
\hline 3 & 34 & Right larger & None & None & & Left hemiplegia & & Recovered \\
\hline $\begin{array}{l}4 \\
5\end{array}$ & 22 & $\begin{array}{l}\text { Constricted } \\
\text { cn same side }\end{array}$ & None & About is hr. & $55^{-60}$ & Right hemiparesis & Bloody $35^{\circ}$ & Recovered \\
\hline 6 & 34 & Right larger & None & None & Normal & Left Babinski & & Recovered \\
\hline 7 & & Right larger & None & None & $55^{-60}$ & Left hemiplegia & Bloody & Di \\
\hline 8 & $4 I$ & Left Iarger & Lt. 3rd & None & $50-60$ & Right hemiparesis & & Recovered \\
\hline 9 & 8 & Right larger & Lt. 3rd & $14-18$ hrs. & $55-60$ & Left hemiparesis & & Recovered \\
\hline 10 & 26 & Right larger & Rt, 3rd & I 2-I 4 hrs. & $120-130$ & Bilateral signs & & Recovered \\
\hline I I & I I & Right Iarger & None & 2 hrs. & $50-60$ & $\begin{array}{l}\text { Left hemiplegia } \\
\text { Bilateral Babinski }\end{array}$ & & Died \\
\hline 12 & 46 & Right larger & None & Drowsy throughout & Normal & None & & Recovered \\
\hline I3 & 54 & Right & Non & $\begin{array}{l}\text { Drowsy throughout } \\
\text { Disorient. }\end{array}$ & Normal & Left Babinski & & $\operatorname{Rec}$ \\
\hline 14 & Io & Left larger & Lt. 3rd & $10-12$ hrs. & $45-60$ & Right & Bloody 600 & $\operatorname{Re}$ \\
\hline Is & $3^{6}$ & Right larger & None & $\begin{array}{l}31 \text { days with peri- } \\
\text { ods of disorient. }\end{array}$ & Normal & Left he & & \\
\hline 16 & 53 & Right larger & None & Drowsy throughout & $60-65$ & Left hemiplegia & & Recovered \\
\hline
\end{tabular}

Note that in three cases operation was performed seven, nine, and thirty-one days after accident, respectively. The pulse rate is uniformly low in the greatest majority. Focal signs were present in fourteen cases. Dilated pupil on the side of the lesion with paralysis of the opposite half of the body was present in thirteen cases.

is seen with sufficient frequency to warn the physician of its possibility. That such a state may be brought about is to be explained on the basis of either a contrecoup involvement of the cortex on the opposite side by pressure from the enlarging clot, or more frequently by contrecoup lesion of the cortex at the time of the accident.

In the greatest majority, the presence of a definite neurologic finding as such is not an indication for operation. The mode of appearance of said neurologic finding is much more significant. Hemiplegia seen immediately following an accident has a plegia caused by contusion and laceration of motor centers appears immediately after injury. A combination of minor contusions of the motor centers and edema of the brain due to head injury may give the picture of a progressive paralysis. However, the spinal fluid in such a case is bloody and its pressure is not so high as in cases of extradural or subdural hemorrhage.

5. Cbanges in Spinal Fluid Findings. Spinal fluid findings are very important. The blood content of the spinal fluid is of prognostic and diagnostic significance. Bloody spinal fluid does not rule out an extradural hemorrhage of benign propor- 
tions. In all cases of middle meningeal hemorrhage in this series spinal puncture when performed yielded bloody fluid. Of course, when the fluid is markedly bloody, the possibility of associated brain damage with massive intracerebral hemorrhage should be kept in mind. Bloody spinal fluid

TAble II

MIDDLE MENINGEAL HEMORRHAGE (OPERATEd CASES) State of Consciousness

Lucid interval........... 6

Unconscious throughout.... 7

Drowsy with disorientation. . 3

Pupils

Large on same side........ I3

Large on opposite side...... I

Equal............... 2

Extra-Ocular Palsies

Third............... 4

Fourth............ I

Sixth.............. I

Focal Signs

Present............. 14

Not present........... 2

Vital Functions

Pulse............... 4 45-6o

Respirations........... 18 8-26

Temperature.......... I $00-102$

Spinal Fluid Findings

Pressure............. 300-650

Bloody.............. In all 5 casespunctured

Results

Recovered............ 14

Died................ 2

Note that in cases of middle meningeal hemorrhage, lucid interval occurred in not more than 40 per cent. There was one case with a dilated pupil on the opposite side. Third nerve paralysis on the same side as the clot occurred in four patients. Focal signs were present in fourteen. Respirations and temperature were within normal limits, usually with a low pulse rate, certainly in the beginning. Spinal fluid pressure was uniformly high and the spinal fluid was bloody in each instance. The presence of bloody spinal fluid should not deter operative intervention in cases of middle meningeal hemorrhage. The tendency to attribute the clinical findings in the case to subarachnoid hemorrhage is to be deplored.

does not rule out chronic subdural hematoma. In a goodly number the fluid was either bloody or xanthochromatic.

Spinal fluid pressure obtained by water or mercury manometer is frequently of deciding significance. The pressure is always high particularly early in operative conditions excepting where operation is indicated for mechanical defects (simple and compound depressions). Fluid pressure of 300 and over is significant. In cases where the spinal fluid is definitely bloody with pressure varying between 200 and 300 , the possibility of cerebral contusions and pial tears causing the increased fluid pressure is apparent. Such pressure invariably drops down as the patient slowly recovers. In case of an operable condition, the pressure stays up or goes higher, except when the patient is very ill. A pressure of 150 is compatible with middle meningeal hemorrhage. This was true in one of our cases.

Extremely high spinal fluid pressure (750 plus) tends to become lower in patients who are progressively getting worse, as is well brought out by Browder and Meyers. At times a subnormal spinal fluid pressure is obtained in a patient who is evidently fatally ill. It is difficult to explain such low pressure, particularly in the presence of marked cerebral damage as shown by bloody spinal fluid. Possibly it is due to a deranged circulatory mechanism in the nervous system even though the general body circulation may be working at par or above par.

In patients who remain drowsy or disoriented for days or weeks, the presence of high spinal fluid pressure (300 and over) is a strong argument in favor of operation. In such cases, chronic subdural hematoma and occasionally an extradural clot may be uncovered.

Summary of Signs and Symptoms. It is evident from the above discussion that a combination of signs and symptoms may spell operative intervention. For example, low pulse rate of itself is not as significant as when associated with increasing drowsiness. With constant attention to the patient's condition and its varying manifestations, one usually arrives at a sane conclusion as to the proper procedure. It should be emphasized that each case of head injury should be individually treated on its own merits. There is sufficient variation in the manifestations of the pathologic processes to make a routine policy worthless. This will become more evident in the following discussion of extradural hemorrhage, acute and chronic sub- 
dural hemorrhage, subdural collection of spinal fluid and certain cases of contusions and lacerations of the brain.

\section{EXTRADURAL HEMORRHAGE}

Extradural hemorrhage may be brought about by bleeding from bone, sinuses, meningeal vessels and emissary veins. Diploic bleeding is not usually of sufficient size to cause symptoms. We have seen fairly large extradural clots from rupture of the occipital emissary vein with depressed fracture in this vicinity. In none were there evidences of pressure symptoms from the clot. As a rule a discussion of extradural hemorrhage implies the group with bleeding from the middle meningeal artery. In the present series sixteen out of nineteen cases had rupture of the middle meningeal artery, two had rupture of the anterior meningeal and one was associated with tear of the lateral sinus.

In the typical case, the diagnosis of middle meningeal hemorrhage is easy. The usual story of head injury followed by a period of lucid interval which is then followed by progressive drowsiness, dilated pupil on the same side and evidences of paralysis on the opposite side makes the diagnosis a simple one. However, such a history may obtain with other than hemorrhage from the middle meningeal artery. We have seen this syndrome with acute subdural hemorrhage, edema of the brain and subdural collection of spinal fluid.

The absence of lucid interval is no argument against the diagnosis of middle meningeal hemorrhage and in some cases of benign outcome. The lucid interval is present if the hemorrhage is slow and there is no associated severe brain injury. It may be absent if the hemorrhage is very rapid, causing death two to three hours following the accident, or if there is associated severe brain damage. Marked disorientation alternating with lucid interval was observed in three cases. These people were operated on six, eight, and thirty-two days after the accident, respectively.
Dilated pupil on the side of the lesion associated with paresis or paralysis of the opposite half of the body was observed in twelve of sixteen cases. In three the pupils were equal and in one case the pupil was Iarger on the opposite side. In the latter, the hemiparesis pointed to the lesion on the side with the constricted pupil. Extraocular palsies were present in four of sixteen cases. It is reasonable to assume that the presence of such a palsy implies a more basal hemorrhage with the arterial tear in the vicinity of the foramen spinosum. With hemorrhage in this situation there is greater likelihood of implication of extraocular nerves as they course through the superior orbital fissure. Hemorrhage arising from rupture of the posterior branch of the middle meningeal artery compresses the lateral surface of the hemisphere and it is not usually associated with extraocular paIsy. With tear of the posterior branch, there is greater likelihood of pupils equal in size. Hemiplegia or hemiparesis was present in fourteen of sixteen cases.

In an earlier communication, we discussed the similarity of Weber's syndrome (alternating oculomotor paralysis) and some cases of middle meningeal hemorrhage. This syndrome was seen in four cases. Each had third nerve palsy on the same side as the lesion with paralysis or paresis of the opposite half of the body. It is important to note this similarity, for the location of the lesion as described by Weber in cases of alternating oculomotor paralysis is in the midbrain, whereas, these cases of extradural hemorrhage proved beyond doubt that such a syndrome may be brought about by an enlarging clot above the tentorium. The third nerve paralysis is brought about by pressure against the third nerve in its course through the superior orbital fissure and the enlarging clot at the same time causes a paresis or paralysis of the opposite half of the body by pressing against the motor cortex.

Subdural hemorrhage caused by rupture of the middle meningeal artery internal to the dura was seen in one case. There was 
also an extradural clot in this patient. The possibility of massive subdural hemorrhage from rupture of the middle meningeal artery internal to the dura is well admitted, such example but we have seen three others in cases which were not operated on. In one case, this temporosphenoidal clot weighed between 35 and $40 \mathrm{Gm}$.

TABLE III

OPERATED CASES OF CHRONIC SUBDURAL HEMATOMA

\begin{tabular}{|c|c|c|c|c|c|c|c|c|}
\hline Case & Etiology & $\begin{array}{l}\text { Ocular } \\
\text { Changes }\end{array}$ & $\begin{array}{l}\text { Frac- } \\
\text { ture } \\
\text { of } \\
\text { Skull }\end{array}$ & Focal Signs & $\begin{array}{l}\text { Loca- } \\
\text { tion of } \\
\text { Hema- } \\
\text { toma }\end{array}$ & $\begin{array}{l}\text { Spinal } \\
\text { FIuid }\end{array}$ & Operation & Results \\
\hline I. C. G. & Auto & None & No & $\begin{array}{l}\text { Aphasia. Left } \\
\text { hemiparesis }\end{array}$ & Left & & $\begin{array}{l}\text { Left subtempo- } \\
\text { r a I d eco m- } \\
\text { pression }\end{array}$ & Recovered \\
\hline 2. J. R. & Boxing & None & Yes & $\begin{array}{l}\text { Right Jackson- } \\
\text { ian once }\end{array}$ & Left & 350 clcar & $\begin{array}{l}\text { Bilatcral tre- } \\
\text { phine }\end{array}$ & Recovered \\
\hline 3. H. C. & $\begin{array}{l}\text { Hit o } n \\
\text { head }\end{array}$ & None & Yes & $\begin{array}{l}\text { Headaches, } \\
\text { more to the } \\
\text { left }\end{array}$ & Left & $45^{\circ}$ clear & $\begin{array}{l}\text { Bilateral tre- } \\
\text { phine }\end{array}$ & Recovered \\
\hline 4. J. D. & & $\begin{array}{c}\text { Right pupil } \\
\text { dilated }\end{array}$ & No & & Right & & $\begin{array}{l}\text { Right subtem- } \\
\text { poral }\end{array}$ & Recovered \\
\hline 5. F. F. & Football & $\left|\begin{array}{l}\text { C h o k e d } \\
\text { discs }\end{array}\right|$ & No & None & Left & 400 clear & Left trephine & Recovered \\
\hline 6. J.L. & $\begin{array}{l}\text { Rocked on } \\
\text { chair fall- } \\
\text { ing back- } \\
\text { ward }\end{array}$ & $\begin{array}{l}\text { Right pupil } \\
\text { larger }\end{array}$ & No & None & Right & & $\begin{array}{l}\text { Right subtem- } \\
\text { poral } \\
\text { Left trephine }\end{array}$ & Recovered \\
\hline 7. I. G. & Fight & Left 3 rd & Yes & $\begin{array}{l}\text { Right hemi- } \\
\text { paresis }\end{array}$ & Left & $\begin{array}{l}370 \text { slightly } \\
\text { bloody }\end{array}$ & $\begin{array}{l}\text { Left subtcmpo- } \\
\text { ral decompres- } \\
\text { sion }\end{array}$ & Recovered \\
\hline 8. E. N. & Auto & None & Yes & Left hemiplegia & Right & $45^{\circ}$ clear & $\begin{array}{l}\text { Bilateral suh- } \\
\text { temporal de- } \\
\text { pression }\end{array}$ & Recovered \\
\hline 9. J. O. & Auto & None & Yes & $\begin{array}{l}\text { Left hemipare- } \\
\text { sis }\end{array}$ & Right & 400 clear & $\begin{array}{l}\text { Bilateral de- } \\
\text { compression }\end{array}$ & Recoviered \\
\hline Iо. C. R. & Shot & None & No & $\begin{array}{c}\text { Aphasia, right } \\
\text { hemiplegia }\end{array}$ & Left & $\begin{array}{l}\text { Bloody in- } \\
\text { creased } \\
\text { pressure }\end{array}$ & $\begin{array}{l}\text { Left subtempo- } \\
\text { ral decompres- } \\
\text { sion }\end{array}$ & Recovered \\
\hline I . E. D. & Fight & $\begin{array}{l}\text { Left pupil } \\
\text { larger }\end{array}$ & No & $\begin{array}{l}\text { Suggestive } \\
\text { right hemi- } \\
\text { paresis }\end{array}$ & L.eft & 400 clear & $\begin{array}{l}\text { Left subtempo- } \\
\text { ral } \\
\text { Right trephinc }\end{array}$ & Recovered \\
\hline I2. M. O. & Fight & None & Yes & $\begin{array}{l}\text { Right hemi- } \\
\text { paresis }\end{array}$ & Left & 450 & $\begin{array}{l}\text { Left decom- } \\
\text { pression }\end{array}$ & Recovered \\
\hline 13. C. O. & Auto & None & Yes & Aphasia & Left & $\begin{array}{l}300 \text { slightly } \\
\text { bloody }\end{array}$ & $\begin{array}{l}\text { Right trephine } \\
\text { L.eft subtempo- } \\
\text { ral }\end{array}$ & Recovered \\
\hline
\end{tabular}

Among the operated cases of chronic subdural hematoma ocular manifestations occurred among five out of thirteen. There was fracture of the skull in seven cases. The site of the fracture does not necessarily indicate the side on which the clot may be found. The focal signs were frequent in this group but in a certain number some of these signs had disappeared completely by the time the patient entered the institution for treatment. For instance, although Case 2 had a Jacksonian epilepsy, this occurred only once and for several weeks he complained of severe headaches and at times became stuporous. The spinal fluid findings showed increased pressure in every one of the cases punctured. Xanthochromatic or bloody spinal fluid was obtained in three cases.

but this is undoubtedly a rare occurrence. A serious complication of middle meningeal hemorrhage is an occasional massive clot in the temporosphenoidal lobe on the same side. In the operated group there was one
The general appearance of the patient is of great importance. In the absence of severe associated brain damage, patients. with middle meningeal hemorrhage usually do not look very ill. The pulse rate is almost 
always low in the beginning. The respirations are not elevated and temperature reads between 100 and 102 rectally. The onset of symptoms is gradual, the patient showing more signs with every elapsed hour or more. The gradual onset of signs and symptoms is an important diagnostic criterion, although we may occasionally get the same picture with acute subdural hemorrhage or edema of the brain.

At times the position of fracture is of localizing significance, although in the
Slightly bloody spinal fluid or severely bloody spinal fluid does not rule out middle meningeal hemorrhage. AIl but one of the punctured cases recovered.

Table IV gives a summary of the cases as weIl as the signs and symptoms shown. Of great interest is the relative infrequency of lucid interval. It is also significant to observe that in a few patients disorientation alternating with periods of lucidity was the paramount change in state of consciousness. It may be assumed that

TABLE IV

FOCAL SIGNS IN OPERATED CASES OF ACUTE SUBDURAL HEMORRHAGE, SUBDURAL COLLECTION OF FLUID, EDEMA AND CONTUSIONS OF BRAIN

\begin{tabular}{|c|c|c|c|}
\hline & $\begin{array}{l}\text { Acute Subdural } \\
\text { Hemorrhage }\end{array}$ & $\begin{array}{c}\text { Subdural Collection } \\
\text { of Spinal Fluid }\end{array} \mid$ & $\begin{array}{l}\text { Edema of Brain } \\
\text { Cerebral Contusions } \\
\text { and Subarachnoid } \\
\text { Hemorrhage }\end{array}$ \\
\hline 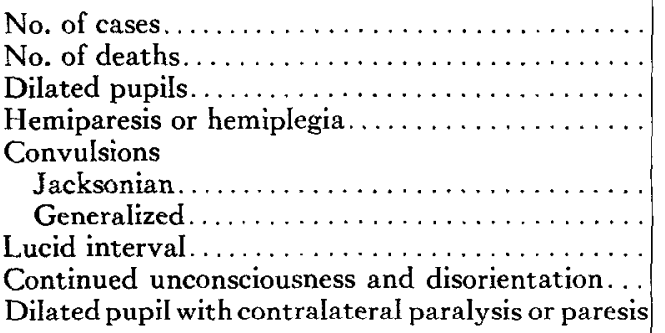 & $\begin{array}{r}11 \\
5 \\
5 \\
5 \\
2 \\
0 \\
2 \\
4 \\
4\end{array}$ & $\begin{array}{r}13 \\
6 \\
5 \\
4 \\
2 \\
0 \\
2 \\
4 \\
2\end{array}$ & $\begin{array}{r}15 \\
8 \\
5 \\
7 \\
2 \\
1 \\
2\end{array}$ \\
\hline
\end{tabular}

It is to be noted that lucid interval occurred in two cases with each of the conditions above enumerated. Dilated pupil on the side of the lesion with hemiparesis or hemiplcgia of the oppositc half of the body accurred in four cases with acute subdural hemorrhage, two cases with subdural collection of spinal fluid and in three cases with edema of the brain, cerebral contusions and subarachnoid hemorrhage. Continued unconsciousness and disorientation was frequently seen among cases with acute subdural hemorrhage and subdural collection of spinal fluid. Jacksonian convulsions were frequent in this group. Although the signs seen in this group may simulate cases of extradural hemorrhage, patients with the latter condition usually look much better certainly in the earlier stages of the disease.

greatest majority the diagnosis should be made on the basis of signs and symptoms. If the head is explored on the side of the fracture shown in the $x$-ray and no pathology is discovered, it is justifiable to explore the opposite side. The spinal fluid cxamination shows high pressure ranging between 300 to 650 by the water manometer. The fluid is bloody in each case punctured, usually mildly so. In one of our cases it was very bloody, but this patient had an associated intracerebral clot in the temporosphenoidal lobe on the same side. among these, the bleeding is sufficiently slow to allow the brain to compensate for space occupied by the clot; hence the absence of motor phenomena and period of lucidity followed by unconsciousness.

The operative technique and the methods used in the treatment of middle meningeal hemorrhage are removal of the clot through subtemporal decompression or osteoplastic flap. Either is preceded by an initial exploratory opening just in front and above or just behind and above the ear, or both. The use of a flexible brain 
spatula of proper dimensions is worthwhile in that it may be introduced in the epidural space and thus a fairly large area may be

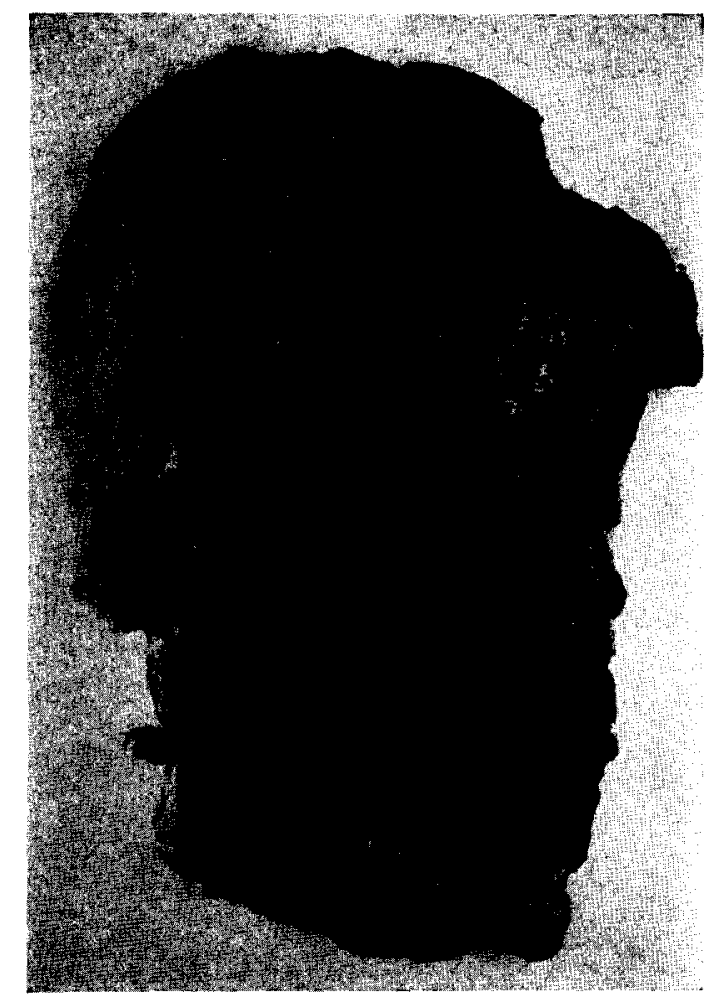

FIG. I. Clot due to middle meningeal artery rupture obtained through an osteoplastic flap. With this procedure a mere complete evacuation of the clot is possible.

inspected. If necessary bilateral trepanation may be resorted to. This was necessary in one of our cases.

We have used general anesthesia more often, assuming that increased intracranial pressure caused by the anesthetic may accelerate the obliteration of the epidural space and minimize postoperative bleeding. Careful work is of course important, but speed is a definite criterion in the results obtained. These patients are usually on the verge of shock, and long drawn out operative technique will not help in the majority. After removal of the clot the bleeding vessel, if found, is ligated. We usually pack the epidural space loosely with iodoform gauze which controls bleeding and cuts down operative time. The packing is removed during the following two days.

\section{CHRONIC SUBDURAL HEMATOMA}

Although a history of minor head injury is frequent among cases of chronic subdural hematoma, the association of this condition with severe brain injury and fracture of the skull has been repeatedly described in the past few years. In the present group of thirteen cases, seven had fracture of the skull. Undoubtedly the reason for such preponderance of associated fracture in this group is due to the rather large fracture service at the Receiving Hospital in Detroit. When chronic subdural hematoma complicates skull fracture with brain injury, a long drawn out state of drowsiness, disorientation, or both may ensue. In such instances there may be drowsiness or disorientation for weeks or months, and patients may even die if the chronic subdural hematoma is not suspected or treated.

Focal signs were present in a great many in this group. Among ocular manifestations, dilated pupil on the side of the lesion was seen in three, third nerve palsy in one, and choked disks in another. Localizing signs were absent in four cases. The most characteristic finding was headache, and this was practically always Iateralized. In two cases definite remissions occurred. The latter occurrence is significant in that chronic subdural hematoma is not always characterized by progression of symptoms and signs. In two cases in this series, the psychic manifestations were the most important symptoms. That patients with chronic subdural hematoma may be sent to insane asylums as mental cases has already been emphasized in the literature.

The spinal fluid findings were indicative of high pressure, ranging between 350 and $450 \mathrm{~mm}$. of water. In three cases the spinal fluid was bloody. Bloody or xanthochromatic spinal fluid does not rule out chronic subdural hematoma.

As concerns cases of fracture of the skuIl who do not recover properly and remain 
disoriented or drowsy for several weeks, that we have found the hemorrhage on the the important thing to remember is that same side, on the opposite side, and in one there may be a complicating chronic sub- case associated with an occipital fracture.

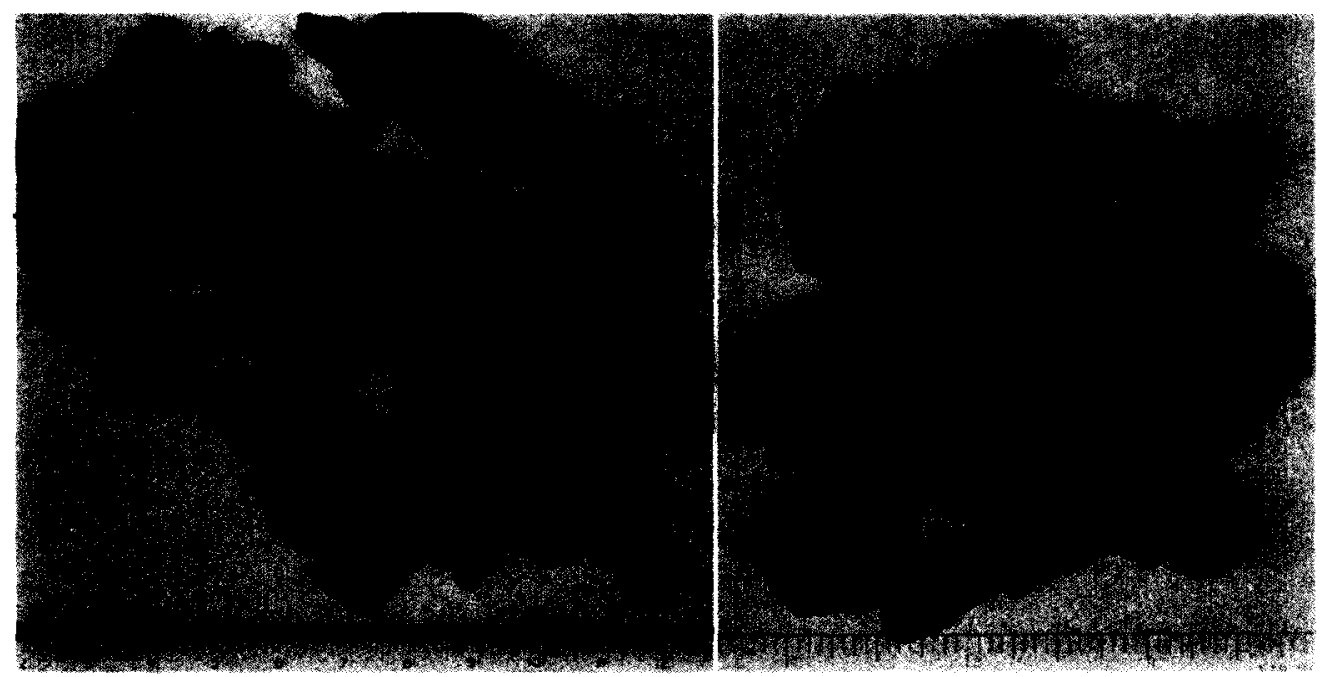

FIG. 2.

FIG. 3.

FIGs. 2 AND 3. Clots obtained from patients shown in Figures 6, 7, 8, and 9.

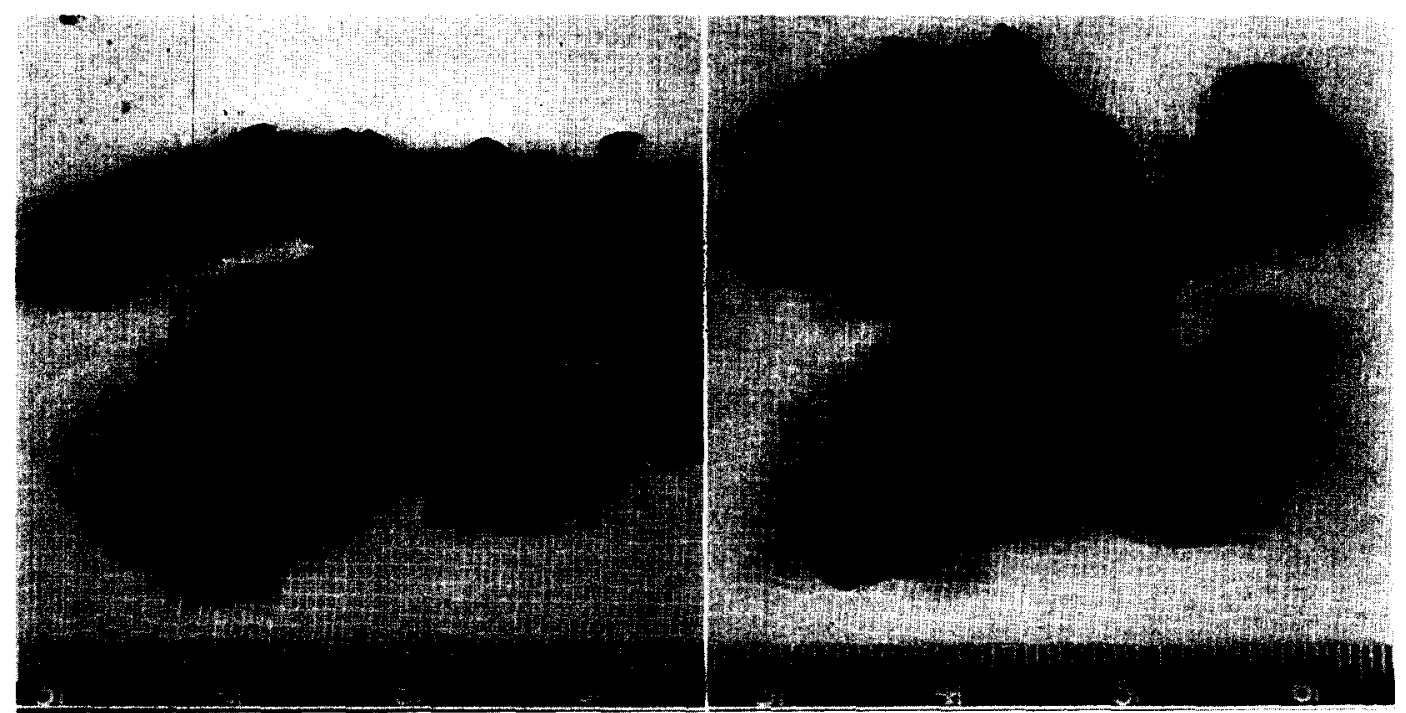

FIG. 4. Shows clot evacuated from epidural space thirty-one days after the accident. In this case the bleeding must have been very slow with gradual receding of the brain to allow for space occupied by the clot. Patient had left hemiplegia with periods of disorientation and drowsiness. The removal of the clot was followed by complete restoration of function to the left half of the body.

dural hematoma. The most important diagnostic criterion in such a case is increased spinal fluid pressure. The site of fracture is of no localizing significance in

FIG. 5. This clot was obtained in a patient with a dilated pupil on the opposite side.

When chronic subdural hematoma is suspected, it may be ruled out by either encephalography or exploratory trephine openings on both sides of the skull.

Organization of the clot in the subdural space is begun immediately and evidences may be seen under the microscope in less than twenty-four hours. In a case of acute subdural hemorrhage from boxing, organi- 


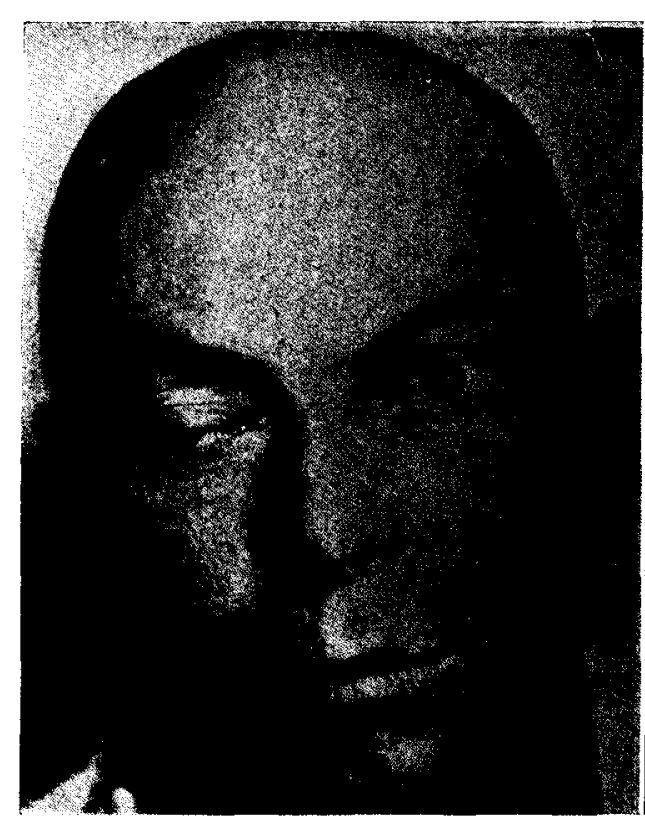

FIG. 6.

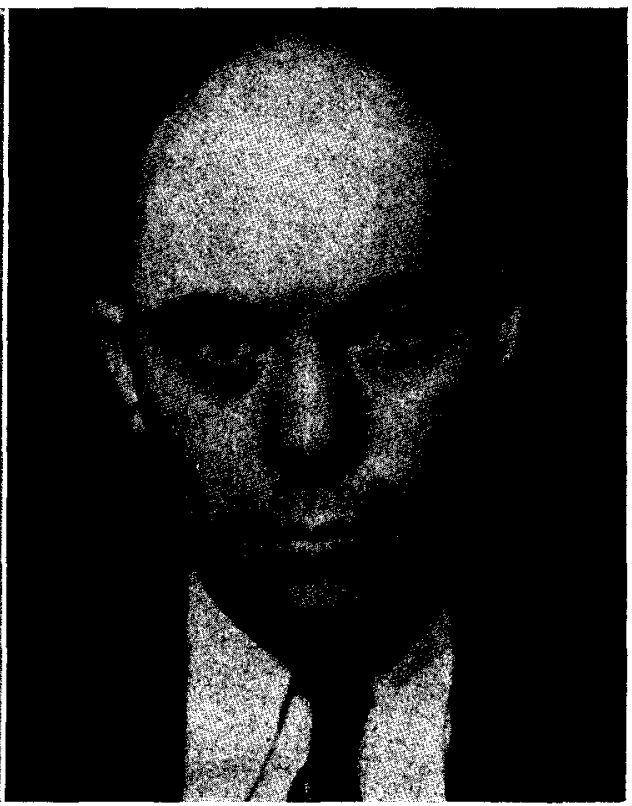

Fig. 7.

FIgs. 6 AND 7. A case of middle meningeal hemorrhage with third nerve paralysis. Recovery of oculomotor function usually obtains in three to frve weeks after operation. The pupil on the affected side usually remains Iarger for a Ionger period. Eventually reaction to light and in accommodation obtains.

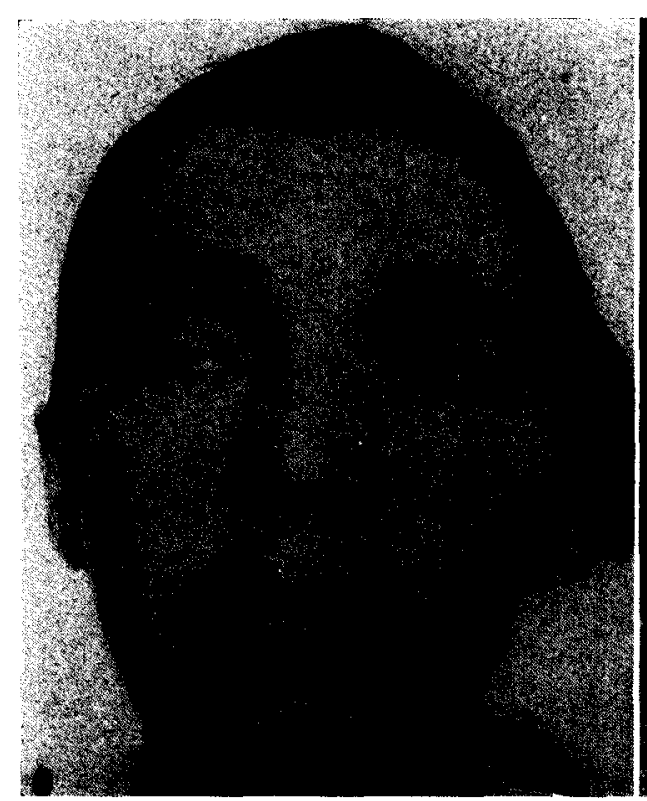

FIG. 8.

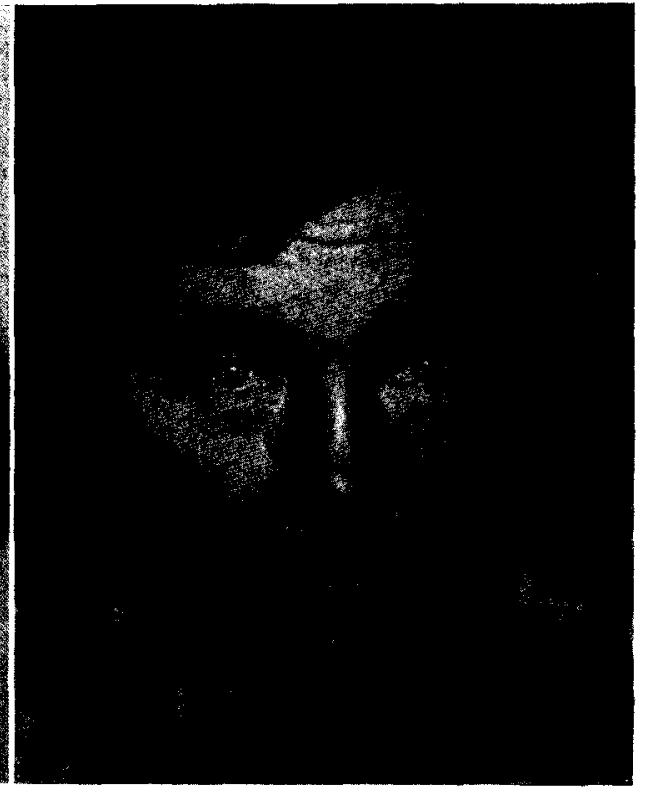

FIG. 9.

Figs. 8 AND 9. Middle meningeal hemorrhage with right third nerve paralysis. In this case the pupils became equal three months after operation. 
zation from the dural side was evident in sixteen hours. This organization can only obtain on the dural side, whereas, due to operation, this opening into the subdural cyst is sealed off, thus bringing about the same physical and chemical relationship

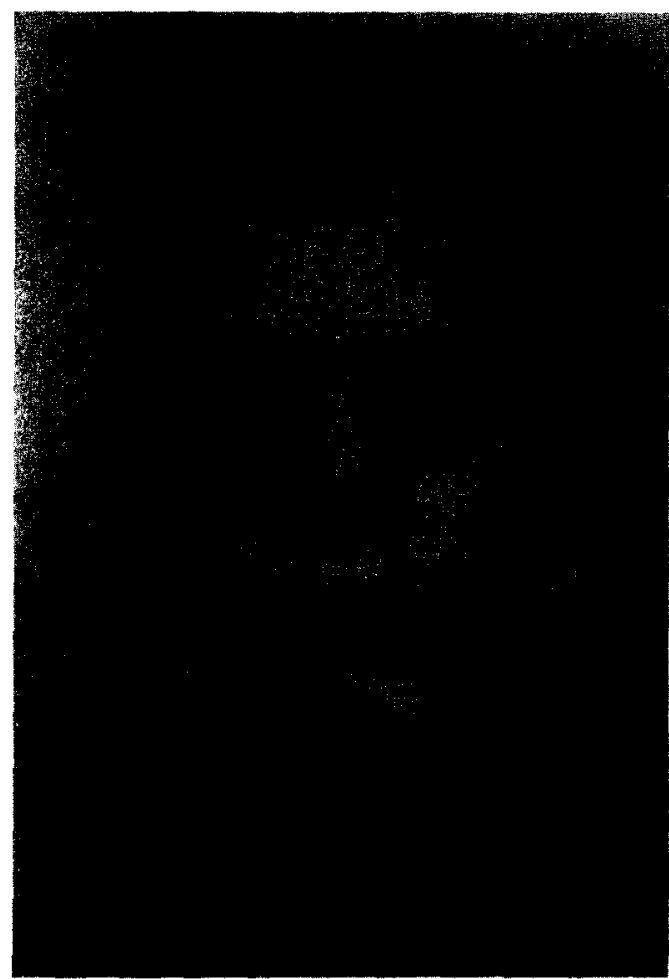

FIg. Io.

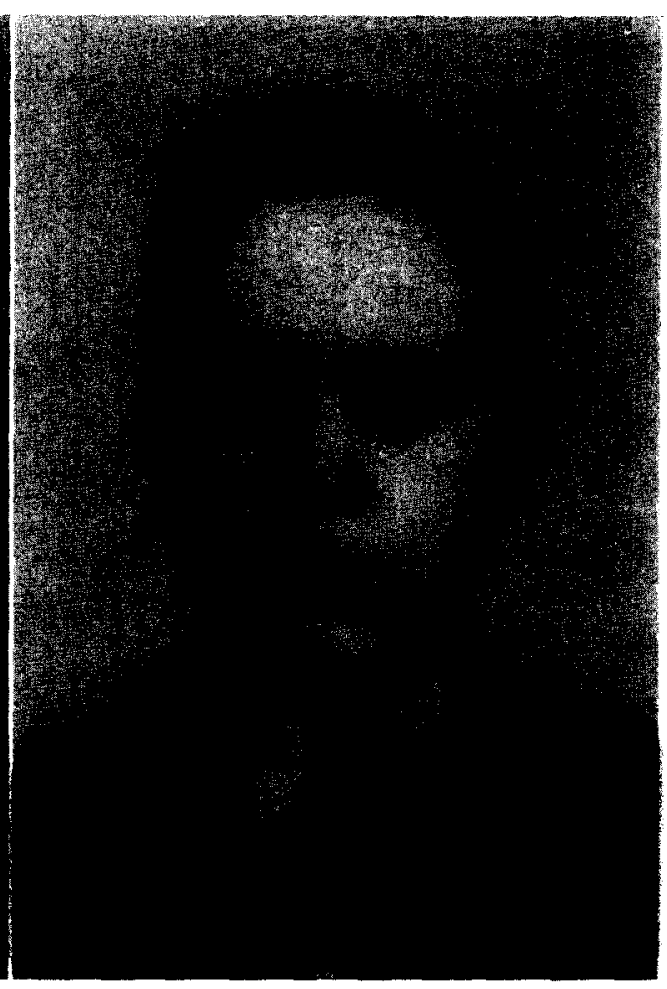

FIG. II.

Figs. io AND 11. Case of middle meningeal hemorrhage with left oculomotor paIsy. As shown in Figure I I, patient still had a dilated pupil on the left side, two and a half months after operation. This boy had bloody spinal fluid with a pressure of $600 \mathrm{~mm}$. of water. He was extremely ill and would have died within a few hours. The presence of grossly bloody spinal fluid should not be a factor in excluding middle meningeal hemorrhage of benign proportions as proven in this case.

lack of blood supply, the arachnoid does not help in any way.

The thought recently expounded by Gardner and others concerning the origin and formation of large cystic contents in chronic subdural hematoma is interesting and worthwhile. It is suggested that there is transference of spinal fluid and tissue fluid into the blood clot by osmosis and diffusion, thus accounting for the progressive cnlargement of the subdural pathology. But it is rather difficult to explain why this same procedure does not reobtain following evacuation of such a subdural cyst through a small opening with no effort being made at removal of the wall of the cyst. It is reasonable to assume that soon after as previously present. Of course, it is assumed that some postoperative bleeding obtains in the cyst cavity. Theoretically such a patient should return for further operative work in a short time. Some of our own cases have gone for longer than three years without any return of symptoms. What happens when the cyst wall is ruptured and the contents evacuated so that there is no return of cystic accumulation, is still a mystery.

The treatment is always surgical. It is preferable to trephine both sides of the skuIl even if the first opening uncovers the pathology. A single trephine opening has been found sufficient to drain the cystic contents and cure the patient. This was 
done in four cases with excellent results. Subtemporal decompression on the side of the lesion was used in the remaining

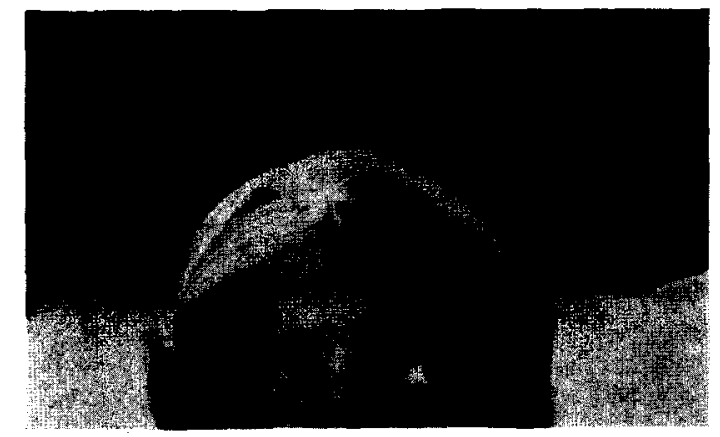

FIG. I 2. Chronic subdural hematoma associated with left third nerve paralysis. Complete return of extraocular movements obtained in eight weeks. The clot was found on the side of the paralyzed eye. In all cases of chronic subdural hematoma bilateral exploratory operation is in order.

cases. In this group no osteoplastic flap was performed for the care of the disease process. We usually leave a rubber drain in the subdural space which is removed in the next two days. If one treats this condition by a single trephine opening, it is advisable to insure complete evacuation of the cystic contents by postural drainage and washing out the subdural space with saline at the time of operation.

\section{ACUTE SUBDURAL HEMORRHAGE}

Acute subdural hemorrhage may be brought about by pial tears, contusion and laceration of nervous tissue. In some cases it was found to be sufficiently extensive to cover the hemispheric surfaces on both sides. In others it was more localized in its distribution and was frequently found along the region of the sylvian fissure of the brain. There is undoubtedly a good reason for such an occurrence, in that the frontotemporal region of the hemisphere is encased rather snugly in the cranial cavity with several sharp boundaries of bone extending into concavities of the brain. This is particularly true of the posterior boundary of the lesser wing of the sphenoid and its extension along the parietal bone. This bony ridge can easily cause laceration and contusion of the frontotemporal junction of the hemisphere when the brain and the bone "crowd" each other in contrecoup lesions. In eleven cases where operation disclosed the presence of subdural clots, indications for operation were quite definite and neurological findings of positive localization were present in all. There was Jacksonian epilepsy in two. Lucid interval was present in two cases. Inequality of pupils was present in five cases. Dilated pupil on the side of the lesion with paralysis or paresis of the opposite half of the body was present in frve cases. Continued unconsciousness and disorientation occurred among four.

There is a pronounced difference between cases of acute subdural hemorrhage and extradural hemorrhage as concerns the general appearance of the patient. The former look much sicker, with increased temperature and definitely increased respirations; this is particularly true in the earlier stages of the condition. Of the eleven patients frve died. In this group of cases, we have not included those with very small subdural clots, as frequently seen with compound fractures and depressed fractures; these do very nicely.

Cases of subdural hemorrhage constitute the more chronic types of head injury, in that if they survive the condition they remain disabled and are confined to a hospital as long as three to five months. It is interesting to note that a number of these after long stay in the hospital because of marked disorientation, in due time recover rather completely their mental function; a majority, however, have marked personality changes.

Indications for operation in this group have becn the progressive character of physical findings. The appearance of a paresis a day or two after the accident, Jacksonian convulsions of increasing severity and not treatable by lumbar puncture, the presence of a dilated pupil, long periods of drowsiness and disorientation tending to 
become more severe, have been some of the factors favoring intervention.

The operation of choice has been subtemporal decompression. A good sized opening is made for decompressive purposes. The use of a brain spatula of appropriate size is of great help to milk the surface of the brain and to rid it of clots. Unless great care is taken in the use of the spatula it may cause much damage to the surface of the brain.

SUBDURAL COLLECTION OF SPINAL FLUID

In some cases the most important pathologic finding at operation was the presence of a large amount of spinal fluid in the subdural space. Whether this fluid, which may be trapped in the subdural space, actually causes sufficient pressure to bring about the clinical findings, is at times questionable. In a few instances such a cause and effect relationship may be satisfactorily proved by excellent postoperative recovery; in others, the operative intervention and evacuation of the subdural collection of fluid seem to have little or no effect on the course of the clinical manifestations. That there may be associated brain damage cannot be denied, for in a great many examples of head injury a combination of several pathologic entities may obtain at the same time. Small amounts of subdural fluid found at operation are not classified under this heading. Here, an ounce or more has been obtained in all of the thirteen cases classified under this category. Indications for operation were evident in all the cases. There was a lucid interval in two followed by progressive drowsiness and disorientation. Drowsiness and marked disorientation were present in four cases. Jacksonian convulsions were present in two. Third nerve paralysis was present in one. Hemiparesis was present in four and inequality of pupils was seen in five patients.

In two patients the results were miracuIous. Consciousness was recovered soon after operation. There were six deaths. Such high mortality emphasizes the correctness of the assumption that undoubt- edly most of these patients have associated damage to the brain. For instance, two autopsy cases in this group showed petechial hemorrhages throughout the nervous system.

We strongly suspect that hydroma of the brain as described by Dandy is undoubtedly the same as collection of subdural spinal fluid in the majority. External hydrocephalus associated with tears in the arachnoid membrane can allow accumulation of spinal fluid in the subdural space, thus bringing about this condition. It is possible that once this situation exists a vicious circle may obtain. With accumulation of subdural fluid suffcient to cause pressure on the brain, more fluid may be pressed out of the brain and its cavities to add to the size of the subdural collection.

\section{EDEMA OF THE BRAIN, CONTUSION OF THE BRAIN SURFACE, SUBARACHNOID HEMORRHAGE}

In fifteen patients, the pathologic findings at operation were those of suffused brain surface with marked edema, and in some cases with subarachnoid hemorrhage.

The indications for operation were lucid interval in two, dilated pupil in frve, hemiplegia and hemiparesis in seven, generalized convulsions in one, and Jacksonian convulsions in two cases. The greatest majority of these patients were operated on soon after entrance into the hospital, certainly within the first twentyfour hours. They were all very ill from the beginning. There were eight deaths and in the greatest number the operation was resorted to with a meager hope that a condition of benign proportions might be uncovered. These were truly undertaken for the purpose of exploration.

\section{COMMENT ON OPERATED CASES}

On glancing over the indications for operation in cases of extradural hemorrhage, acute subdural hemorrhage, subdural collection of spinal fluid, marked edema of the brain and subarachnoid 
hemorrhage it is apparent that a great many had identical signs and symptoms. For instance, lucid interval was seen not only in cases of extradural hemorrhage but also among cases with different pathology. Paralysis or paresis of one-half of the body associated with dilated pupil on the opposite side was seen frequently in cases of acute subdural hemorrhage, edema and contusion of the brain and subarachnoid hemorrhage. It is therefore evident that a great many patients were operated on because of a combination of certain signs and symptoms with the hope that the uncovered pathology would be of benign proportions. I feel that intracranial exploration in cases with definitc findings is justified. The results will not all be satisfactory, but were one to follow a more conservative course I am sure one would allow the exitus of many a patient with an operable condition of the intracranial contents.

\section{SUMMARY}

I. In the majority of cases of middle meningeal hemorrhage there are neurologic signs implicating the cortex on the effected side. Widely dilated pupil on the same side is seen frequently, although one case in this series had dilated pupil on the opposite side. Pupils equal in size do occur; this was true in two cases in this series.

2. Bloody spinal fluid of varying concentration does not rule out middle meningeal hemorrhage. In this series all punctured cases had bloody spinal fluid. To assume that the condition is one of subarachnoid hemorrhage because of the bloody spinal fluid is a grave mistake in these cases.

3. Lucid interval may be absent in middle meningeal hemorrhage. This was true in more than half of the cases in this series. Lucid interval may be wiped out because of (I) very rapid hemorrhage and (2) associated severe damage of the brain.

4. Lucid interval was seen not only in cases of middle meningeal hemorrhage but also in those with acute subdural hemor- rhage, subdural collection of spinal fluid and edema of the brain.

5. Chronic subdural hematoma usually follows slight injury to the head, but in this series its association with severe brain injury and fracture of the skull is brought out. Seven cases had associated fracture of the skuII.

6. The association of chronic subdural hematoma and relatively severe brain injury should be suspected in patients who remain unconscious, drowsy or disorientated for several weeks. Particularly if the spinal fluid pressure is high, an exploratory operation is justifiable.

7. When the question of cranial exploration arises, cases of head injury should be treated individually and if certain signs obtain operative intervention should be effected. In the presence of the proper signs exploration is justifrable even though results may not be favorable. In this clinic we are particularly impressed by a combination of all or some of the following signs as indication for exploration:

A. Dulling of the conscious state leading to unconsciousness or progressive deepening of an unconscious state already present.

B. Presence and progression of localizing signs rather than neurologic signs implicating the entire nervous system.

C. Increase in spinal fluid pressure.

D. Low pulse rate (in some cases).

\section{REFERENCES}

I. Browder, J., and Meyers, R. Am. J. Surg., 3 I : 403, 1936.

2. Cassassa, C. B. Proc. New York Patb. Soc., 24: 101 , 1924.

3. CoHen, I. Arcb. Neurol. Psycbiat., I8: 709, 1927.

4. Cushing, H., and Putnam, I. K. J. Nerv. eo Ment. Dis., 65: 260, 1927.

5. DANDY, W. E. Practice of Surgery. I2: 295, W. F. Prior Co.

6. Gardner, W. J. Arcb. Neurol. of Psycbiat., $27: 847$, 1932.

7. Grant, F. C. Surg., Gynec. eo Obst., 36: $25 \mathrm{I}, 1923$.

8. Gurdjian, E. S. Arcb. Neurol. o Psycbiat., 28: 26, 1932.

9. NaffZiger, H. C. J. A. M. A., 82: 175 I, 1924.

Io. PEET, M. M. Indust. Doctor, 5: 7, 1927.

i i. VonBergmann, E. System of Practical Surgery. I: 206, 1904. Lea Bros. \& Co. 